\title{
Innovative Teacher Education with the Augmented Reality Device Microsoft HoloLens-Results of an Exploratory Study and Pedagogical Considerations
}

\author{
Corinne Wyss ${ }^{1, *} \mathbb{C}$, Wolfgang Bührer ${ }^{2}$, Florian Furrer ${ }^{3}$, Adrian Degonda ${ }^{4} \mathbb{D}$ and Jan A. Hiss 5 \\ 1 School of Education, University of Applied Sciences and Arts Northwestern Switzerland, \\ 5210 Windisch, Switzerland \\ 2 Department of Secondary I Education, Zurich University of Teacher Education, 8090 Zurich, Switzerland; \\ wolfgang.buehrer@phzh.ch \\ 3 Department of Research and Development, Zurich University of Teacher Education, 8090 Zurich, Switzerland, \\ florian.furrer@phzh.ch \\ 4 Department of Continuing Education and Consultancy, Zurich University of Teacher Education, \\ 8090 Zurich, Switzerland; adrian.degonda@phzh.ch \\ 5 Department of Chemistry and Applied Biosciences, ETH Zurich, 8093 Zurich, Switzerland; \\ jan.hiss@pharma.ethz.ch \\ * Correspondence: corinne.wyss@fhnw.ch
}

Citation: Wyss, C.; Bührer, W.; Furrer, F.; Degonda, A.; Hiss, J.A. Innovative Teacher Education with the Augmented Reality Device Microsoft HoloLens-Results of an Exploratory Study and Pedagogical Considerations. Multimodal Technol. Interact. 2021, 5, 45. https://doi.org/ $10.3390 / \mathrm{mti} 5080045$

Academic Editors: Gokce Akcayir, Nikolaos Pellas, Heinrich Söbke, Yun Wen and Mark Billinghurst

Received: 20 April 2021

Accepted: 6 August 2021

Published: 13 August 2021

Publisher's Note: MDPI stays neutral with regard to jurisdictional claims in published maps and institutional affiliations.

Copyright: (c) 2021 by the authors. Licensee MDPI, Basel, Switzerland. This article is an open access article distributed under the terms and conditions of the Creative Commons Attribution (CC BY) license (https:// creativecommons.org/licenses/by/ $4.0 /)$.

\begin{abstract}
Augmented Reality (AR) tools are increasingly finding their way into education settings. Although their use is still not widespread in educational contexts, the research literature indicates their potential and effectiveness. However, overall and specifically for the education sector there are still numerous research gaps. This study investigates how the use of head-mounted AR displays such as the Microsoft HoloLens can change learning and what needs to be considered from a didactic perspective. The researched sample consists of 18 student teachers with a nature and technology teaching profile of a German-speaking university of teacher education. The data collection included a written questionnaire, video recordings of a teaching unit with HoloLens examining molecular structures, and one-to-one semi-structured interviews. The results of questionnaires and interviews presented in this paper show that all students were highly motivated to work with this technology in teacher education. The usability of the HoloLens was rated very satisfactory, although many students expressed minor problems. Most students attributed a positive impact on learning to the AR device and stated that the usage of the devices increased their motivation for learning the topic. Overall, the results show that the use of AR in teacher education is considered very valuable and should be increasingly employed in the future.
\end{abstract}

Keywords: Augmented Reality (AR); teacher education; student teachers; explorative study; science and technology; molecules; Microsoft HoloLens; head-mounted display; pedagogical approaches

\section{Introduction}

Through the rapid development of digital technologies within the last few years, technologies such as Augmented Reality have become more widely available and are currently used in various domains. AR is becoming increasingly important for the education sector through the development of suitable practical applications [1]. On the one hand, these technologies have led to challenges in the education sector (e.g., problems with the exaggerated usage of smartphones and corresponding distractions of the learning processes [2]); on the other hand, they may offer new perspectives and possibilities, as media and technologies can be used to facilitate teaching and learning. Augmented Reality (AR) is attributed a particularly great potential: "One of the most promising technologies that currently exists is Augmented Reality (AR), which allows a combination of real-world elements captured through a camera with multimedia elements such as text, images, video, 
or 3D models and animations" [3] (p. 752). Previous studies on the use of AR in education have impressively demonstrated its positive effects on teaching and learning processes. However, it is also emphasized that there are still major research gaps, particularly in the field of education [4]. The present study is intended to provide information on how AR can support teaching and learning in teacher education and in the education sector in general. It explores the question of what needs to be considered for the conception of corresponding learning scenarios and aims to reveal new possibilities for working with AR in educational settings. In doing so, current research desiderata will be addressed.

Augmented Reality (AR) refers to a direct or an indirect view of a physical, real environment that has been enhanced by adding virtual computer-generated information. AR is interactive and is used to combine real as well as virtual objects in the three-dimensional space. While Virtual Reality (VR) technology completely immerses the user in a synthetic world without the ability to see the real world, AR technology in contrast expands the sense of reality by superimposing virtual objects and cues on the real world in real time. AR enhances the user's perception of and interaction with the real world and aims to simplify or improve the user's experience by bringing virtual information not only into their immediate environment, but also into any indirect view of the real environment [5]. The Milgram Reality-Virtuality Continuum is often used to visually illustrate the different concepts (see Figure 1). The scale ranges from a completely real environment (reality) to a completely virtual environment (virtuality). Within this continuum, the space between the real environment and the virtual environment is called Mixed Reality (MR). MR is defined as an environment in which the real world and the virtual world are combined. As can be seen in Figure 1, MR expands between Augmented Reality (AR) on one side and Augmented Virtuality (AV) on the other. While AR is a combination of real and virtual objects and contains a small amount of virtual data, AV is a concept where elements of reality are integrated into a virtual environment that contains more digital data [6].

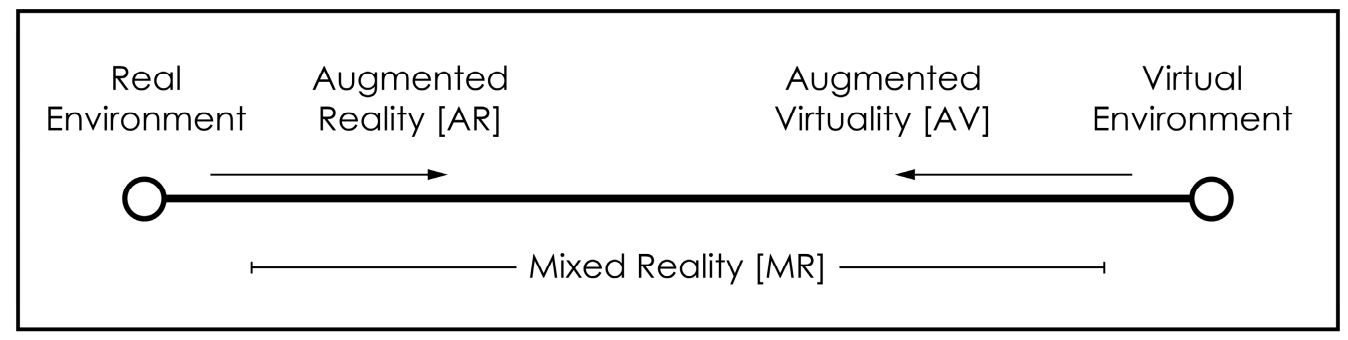

Figure 1. Reality-Virtuality Continuum according to Milgram et al. (1994) [7].

Although Augmented Reality is a rather new technology, there are already numerous research projects that have dealt with it in recent years. These projects are located in various fields, such as medicine, mechanical engineering and technology, architecture, interior design, mathematics, natural sciences, marketing, and transport [8]. Empirical studies have been conducted in education too, although this area is less researched compared with other disciplines. In a systematic literature study by Akçayır and Akçayır [4], a total of 102 publications were found on the topic of AR in education, which covered all publications up to January 2016, including articles from vocational or extracurricular education. After excluding publications that only marginally dealt with AR or were published as an editorial, 68 articles remained. Most of the studies (51\%) dealt with the use of AR with students at the secondary school level (K-12 students), 29\% (twenty studies) investigated the use of AR with university students, and only two studies dealt with teachers. In a recent literature study conducted by Garcòn, Pavón, and Baldiris [9], similar results were found: the target groups of the studies were mainly limited to children (early childhood education and primary education), teenagers (lower and upper secondary education), and Bachelor's or equivalent level students. Of the 61 studies included in the analysis, around $30 \%$ fell into each of these target groups. Postgraduate students (Master's or PhD degrees) were not considered as a target group in any of the selected studies. Interestingly, studies at 
the tertiary education level (especially the Master's degree level) and with (prospective) teachers have so far been significantly under-represented. This is a massive shortcoming. Studies have shown that teachers' comfort with technology in general is a predictor of the probability of its implementation in the classroom. Teachers' attitudes towards technology in turn influence student learning $[10,11]$.

From previous work it is evident that the use of Augmented Reality in education offers many possibilities and advantages to support learning, and this new technology is consistently seen as having enormous potential $[3,8,12,13]$. Many studies have found an impact on learning gains as well as greater motivation and interest. Various studies have also shown that AR can support kinaesthetic learning, visual imagination, and spatial awareness. It increases learners' willingness to engage with scientific topics and facilitates the comprehension of abstract concepts. AR also enhances collaboration among learners and between learners and instructors. This also enhances critical thinking and problemsolving skills, enhances information processing and communication skills, and improves learning transfer (e.g., $[4,6,8,9,13-15])$. AR is therefore seen as a sensible tool for learning 21st-century skills and to enable students to explore contexts that are otherwise impossible or too dangerous $[1,16]$.

Compared with the advantages mentioned, the reported disadvantages are far less extensive. Challenges mentioned include usability, technical problems, and the demands placed on teachers and learners when using the technical devices. Although many new AR applications have entered the market, the individual creation of teaching materials remains cumbersome, which is seen as a potential problem for the widespread acceptance of AR as a teaching tool $[1,16]$. Another problem related to AR systems is multitasking. $\mathrm{AR}$ applications have been found to require much attention, which may be a distraction for learners. In addition, some studies identified a higher time requirement compared with teaching without AR applications and the costs for the acquisition of the devices as disadvantages. Finally, teacher resistance was mentioned as a possible difficulty in implementing AR in educational environments [4,9].

The empirical findings to date on AR in the education sector are very promising, but overall and specifically for the education sector there are still numerous research gaps. "In conclusion, although most of the previous studies showed a positive impact and encouraging results, it is advisable to focus also on pedagogical and learning theory when implementing and developing the AR application since the educational value of AR is not solely based on its features" [6] (p. 663). As with all other technologies, the pedagogical value of AR does not depend solely on the use of the technology, but is shaped by how $\mathrm{AR}$ is designed, implemented, and integrated into formal and informal learning environments $[11,13,17,18]$. In previous studies, this issue was only marginally considered or not addressed at all. So far, AR research and development has been motivated by business interests rather than by projects aimed at improving education [8]. It would be helpful to discover more about how such new technologies could be successfully integrated into existing learning scenarios and which new, innovative learning environments could be developed with them. In this context, there are research desiderata regarding the pedagogical approaches to AR-enhanced learning and the perception of the corresponding learning scenarios by learners [18]. The research projects to date have dealt in particular with AR applications on personal computers, tablets, or mobile phones [4]. Studies using wearable technologies, e.g., gloves, bracelets, or head-mounted displays, are still rare and hardly exist for the education sector [19]. In teacher education in particular, there are hardly any empirical research projects with Augmented Reality. To our knowledge, there are no studies in which head-mounted displays have been used in teacher education.

The aim of the research project "Augmented Reality in Teacher Education. An exploratory study using HoloLens in Science Education" (ALex) is to collect data on experiences using Microsoft HoloLens 1 in teacher education for prospective science and technology teachers and to examine their possibilities and limitations within the framework 
of an explorative study. The project addresses the following overarching Research Question: How does the use of Augmented Reality with HoloLens change learning?

On the basis of the data collection in the project ALex, answers to the overarching question are to be found. In the context of this paper, the following sub-questions will be addressed:

1. What impact does the use of HoloLens have on interest and motivation from the learners' point of view?

2. To what extent is the learning process supported by working with HoloLens from the learners' point of view?

3. What should be considered when working with HoloLens in terms of the didactic setting?

4. What are the possibilities and pedagogical approaches offered by working with HoloLens?

Summarizing our study's findings, the experiences gained are very encouraging. The prospective teachers who were involved in the project were excited by the possibilities of the new technology: according to the students' statements, motivation and interest as well as learning can be positively supported by the use of such technologies. From their point of view, it would be desirable to be able to work with HoloLens in the context of teacher education in the future. All of them think it would be beneficial to use HoloLens in the classroom at the lower secondary level and all but one stated that they would use it in their own classroom as a teacher at the lower secondary level. The statements of the students in the interviews as well as the experiences of the project team give valuable indications about how a didactic setting with HoloLens could look. The results are promising and show that there are sensible possibilities for the use of AR in higher education.

In the following, we present our project and selected results. Based on the experiences had in the project, we then outline the possibilities for the use of HoloLens and illustrate what an extended learning scenario with the use of AR in teacher education could look like.

\section{Materials and Methods}

\subsection{Participants}

In different courses at a University of Teacher Education in German-speaking Switzerland, student teachers for science and technology for lower secondary schools (levels 7-9) were informed about the research project and were invited to participate voluntarily. In response to the call, 20 students registered, of which 18 students eventually took part. The group consisted of 10 male and 8 female students. All students attended a Master's program that usually requires 9 semesters to complete. At the time of the project's realization, 2 students were in the 2 nd semester, 11 were in the 4 th semester, and 5 were in the 8 th semester.

\subsection{Research Design}

The teaching unit and the associated data collection were conducted in four groups on different dates in May 2019. Each session required about $2 \mathrm{~h}$ and included the following activities: an introduction by means of a short presentation (approximately $10 \mathrm{~min}$ ), a written paper-based survey of the participants (approximately $10 \mathrm{~min}$ ), an introduction to the handling of HoloLens 1 (10-15 min), work with HoloLens 1 in groups of 2-3 participants according to the working task (15-20 min), and individual interviews with the participants (15-30 min).

\subsection{Contents and Structure of the Teaching Unit}

The chosen topic of the teaching unit was selected based on the following two criteria: (1) it should be of interest to prospective teachers; and (2) it should cover a topic where AR technology is expected to add significant value in terms of facilitating the exploration of content that is otherwise not meaningfully accessible. To match the teachers' profile, which included biology and chemistry, the topic of three-dimensional protein structures 
was chosen. Whereas actual stick and ball representations of molecules are in principle available, they are not easily created for different and more complex molecules [15]. Using the application MoleGram Scientist, user-selected proteins from the open RCBS-Protein database [20] can be displayed without preparatory work. MoleGram Scientist was developed for Microsoft HoloLens 1 by the ETH Zurich in collaboration with the company afca and is not available for the general market. The proteins are downloaded and rendered live during the session using MOE [21]. In addition, a wide range of different representations can be shown per protein, which is not as easily possible with traditional physical models [16]. These representations include the standard stick and ball models, but can also explicitly overlay other physical and chemical properties, e.g., the peptide backbone (as a cartoon representation), which tremendously facilitates understanding certain features of the spatial configuration of complex molecules and is not easily visualizable in an analogue version of a stick and ball model. The created learning sequence makes use of this ability by dynamically and instantly switching between these representations of different properties to answer diverse questions posed to the students. Furthermore, additional properties, such as the solvent-accessible surface, can be overlayed to enhance understanding.

MoleGram Scientist can, in addition to displaying different representations, create different user sessions. Within each session the displays of multiple HoloLens devices are synchronized over the network using a dedicated server at ETH. This enables members of a session to see and manipulate the same protein and therefore work collaboratively in a more natural way on the same item while seeing each other during the interaction and conversation. Different groups can use different sessions simultaneously. To facilitate the collaboration in discussing specific features of the protein hologram, students can place a pointer that is visible to all participants in a session. Furthermore, the possibility during the use of AR to experience and integrate real-world surroundings in contrast to VR makes it possible to use traditional worksheets to provide additional information and therefore to work across media [13] (see Video S1).

HoloLens is a rather new technical development. It was introduced to the American and Canadian markets at the end of March 2016. HoloLens is a head-mounted display that is placed on the head like conventional glasses [22]. In the visual output of the device, artificial objects and information can be projected into the wearer's visual field, which can be interacted with via various gestures as shown in Figure 2.

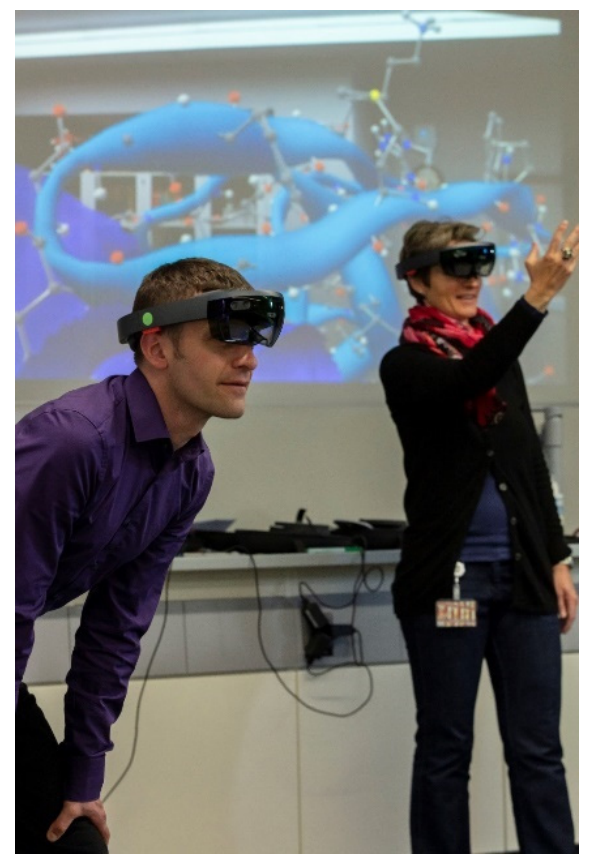

Figure 2. Use case for HoloLens 1. Livestream of the users' view (a stick and ball representation with an overlayed cartoon representation (peptide backbone) in the background. 
The tasks given to the students within the teaching unit were the following:

(a) Visually identify at least one alpha-helix and one beta-sheet structure in the given protein.

(b) Visually identify at least two amino acids of the primary structure in the stick and ball representation of the molecule.

(c) Display and find the ligand (the structural part of a drug molecule) of the protein and identify the spatial structure where the ligand fits in. Students should answer the following question: Why could the ligand be a suitable drug?

In order to be able to solve these tasks, the teaching unit starts with a short repetition of basic concepts for proteins, i.e., an overview of amino acids, peptide bonds, and the primary, secondary (alpha-helix and beta-sheet), and tertiary structure of a protein. This section is followed by an introduction to the different representations the app MoleGram Scientist can display.

After the introduction and a paper-based survey, the students receive a HoloLens device and walk through the user interface training session offered by the HoloLens's Operating System to make themselves familiar with the gestures necessary to operate HoloLens. Following the training session, the teaching person shows the students how to operate the app MoleGram Scientist with a sample molecule. When the app's user interface has been explained, the students can work on the tasks mentioned above in groups of 2-3 students for about 15-20 min. Supplementary Video S1 shows a video sequence of a collaborative task on the molecule with the pdb code 3AID [23] to give an impression of how two overlaying representations are used to identify different aspects of protein structures. The whole procedure is visualized in Figure 3.

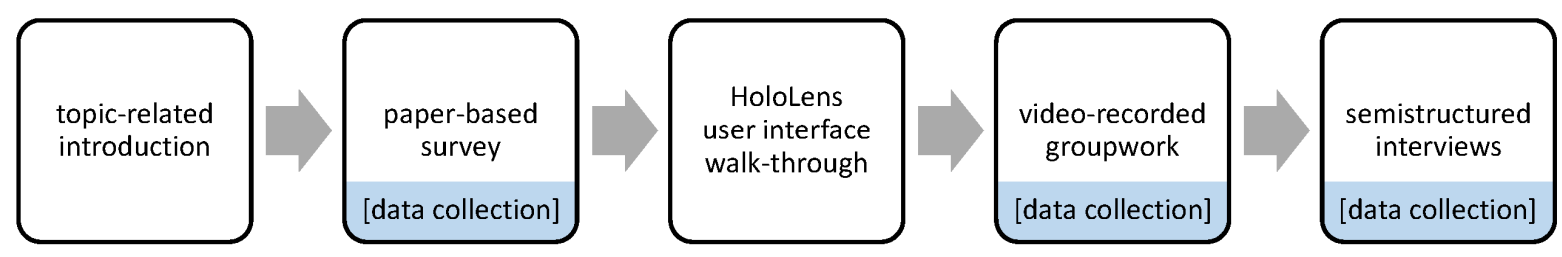

Figure 3. Structure of the participants' program.

\subsection{Data Collection}

The written paper-based survey was conducted as a paper-pencil test. The test sheets were distributed to the participants by the research team on the data collection day and subsequently recollected, ensuring that all questionnaires of the 18 participants were received. The questionnaire was intended to capture the participants' previous experience, motivation, and interest. The survey contained a total of 51 questions consisting of 34 closed-ended questions from validated questionnaire instruments as well as 17 self-constructed, mostly closed-ended questions and one final open-ended question with the possibility to add further comments. The first 22 questions were asked in order to assess the participant's current motivation and momentary attitude toward the task at hand. Eighteen questions of these were taken from the instrument "QCM: Questionnaire on Current Motivation" [24]. This instrument measures four components of current motivation in (experimental) learning and performance situations, namely fear of failure, probability of success, interest, and challenge. Further questions were taken from the short scale "TB: Technology commitment" [25]. The 12 items cover the following subscales: competence in dealing with technology, positive technology consequences, and negative technology consequences. The fourth subscale (enthusiasm for technology) was omitted as self-constructed questions were used that relate specifically to the use of AR technology. The third instrument used was the General Self-Efficacy Short Scale (ASKU: Short Scale for Measuring General Self-efficacy Beliefs) [26], which contains 3 items only. The self-constructed questions were mainly related to surveying previous experiences with AR applications and related attitudes of the students. In addition, some questions were posed about the subject and the students 
were asked about their level of knowledge. The introduction to the operation of HoloLens as well as the subsequent work phase with HoloLens in the groups were videotaped by two stationary cameras in the room. In addition, the video and audio recordings from the head-mounted displays were stored after each work phase.

After the participants had completed the work phase in the groups, they were individually interviewed about their experiences in the group work, about their motivation, and about their interest by means of a semi-structured interview. The interviews were recorded with audio recording devices.

\subsection{Data Analysis}

The results of the paper-based survey were transferred into SPSS. Using the statistical analysis software SPSS, the data were analyzed on a descriptive basis and factor analyses and correlations were calculated.

The video recordings of the lesson were edited, the recordings of the two still cameras and HoloLens of each group were synchronized and merged to make the different video recordings and audio tracks available in one video for easier analysis. For the analysis, a category system was developed (mainly deductive category development) and a structured content analysis was conducted $[27,28]$. The category system comprised the following categories: phase code, interaction, assistive instruction, technical problems, use of interactivity, usability, and learning with Augmented Reality. Each category included several sub-codes. The analysis was carried out with the help of the analysis software MAXQDA. A total of 734 codes were placed on the videos. As the number of video recordings was limited, the analysis was carried out by two project team members in a consensus procedure.

The interviews ranged from 12 to $27 \mathrm{~min}$ in length and were transcribed verbatim manually. For their analysis, a category system was developed (inductive-deductive category development) following the procedure of qualitative content analysis $[27,28]$. The category system comprised the following categories: motivation, interest, didactic setting, usability, and other. Each category included various sub-codes. A structured content analysis was conducted $[27,28]$ using individual themes as the unit for analysis [29]. An instance of a theme can comprise a single word, phrase, sentence, or paragraph in the transcript. As with the video recordings, MAXQDA was used for the content analysis. A total of 699 codes were assigned to the transcripts. Due to the limited number of interviews, the analysis was carried out by two team members of the project in a consensus procedure, analogous to the video analysis. All transcripts were thus analyzed collaboratively, and the codes were jointly discussed and determined.

\section{Results}

Due to the thematic focus of this paper, results of the interviews are mainly reported. However, for the description of the participants in the study, some results of the paperbased survey will be presented first. Due to the extensive nature of the video analysis, these results will be published in a separate paper (paper in preparation).

\subsection{Selected Results of the Paper-Based Survey: Previous Experience and Attitude of the Participants}

The paper-based survey indicates that all 18 students were highly motivated to work with HoloLens. On a scale of 1 to 10 (most positive), the mean value for the corresponding question was almost $9.5(\mathrm{~N}=18, \mathrm{M}=9.44, \mathrm{SD}=0.78)$. The motivation to participate in the teaching unit was also high with a mean value of 9.11 on a scale of 1 to 10 (most positive, $\mathrm{N}=18, \mathrm{SD}=0.90)$. The students' previous theoretical and practical experiences with AR applications were very limited. For the corresponding scale in the questionnaire (number of items $=3, \alpha=0.879$ ), the mean value on a scale of 1 to 10 (highest) is below $2.5(\mathrm{~N}=18$, $\mathrm{M}=2.33, \mathrm{SD}=1.92)$. Despite the students' limited prior experience, they were generally confident in their ability to work successfully with HoloLens, as indicated by a mean score of 5 on a scale of 1 to 7 (highest score) $(\mathrm{N}=18, \mathrm{SD}=0.96)$. In addition, students' attitudes towards AR applications were high with a mean score of 8.33 on a scale of 1 to 10 (most 
positive) on the corresponding scale in the questionnaire (number of items $=3, \alpha=0.615$; $\mathrm{N}=18, \mathrm{SD}=1.25$ ).

\subsection{Selected Results of the Interviews}

The findings of the interview analysis are exemplified with selected quotes from the interviews. As the interviews were conducted in German, the quotes were translated into English by the authors. The symbols (-) in the quotes indicate pauses in speech, with a dash indicating a pause of about one second.

\subsubsection{Usability and Technical Problems}

Although the students only had a short introduction to the handling of HoloLens, all students coped well with the operation. However, almost all students (15 out of 18) also expressed some difficulties. The biggest challenge was to operate the menu of the app and the control of the pointer, as this student explains:

S: I sometimes had some problems, for example (-) that the menu (-) just opened (-). For example, when I fidgeted around. (Laughter) And then I did not know how to close it. And then I was a bit overwhelmed (laughter). (Interview 10C, position 181-185)

Technical problems were expressed by five participants, three of whom were in the same group. For two students, the synchronization of the glasses did not work. Nevertheless, they solved the assignment individually instead of collaboratively. One student had no sound and for two students the glasses did not work at all and had to be exchanged. For the first use of HoloLens with the students, the usability of the devices was rated very satisfactory, and the time required for the introduction was adequate, which was confirmed by 16 of the 18 students:

S: Uh, pff, uh. That is a simple matter of five minutes or so, that is, uh, (-) sufficient for students like us at the university, uh at the university of teacher education. (Interview 09B, position 58)

3.2.2. Research Question 1: What Impact Does the Use of HoloLens Have on Interest and Motivation from the Learners' Point of View?

In the interviews, the students confirmed that they were very motivated to participate in the teaching unit, especially because of the new technology. All students would enjoy working with HoloLens in teacher education in the future, and they see many other areas where working with the technology could be useful, such as biology, chemistry, visual arts, mathematics, and geography. One student puts it this way:

S: I see a lot of possibilities, a lot of potential in it. What you (-) you could do with it! Especially in chemistry, I think it offers the opportunity to visualize things that would otherwise not be possible.

And, also for other subjects I think, (-) plus (-) um, of course it is also an own, um, motivator (-) so it motivates, it would motivate me myself. And, also the pupils, I think. (Interview 10A, position 28-32)

Although the students were already very motivated before the learning unit, twelve students explicitly expressed that their motivation increased even more when working with HoloLens. They were surprised at the possibilities offered by HoloLens and how user-friendly the device is:

S: So, I was quite positively surprised because (-) I am rather convinced that it is, (-) so my previous opinion was that it is probably not very suitable for teaching, and this opinion has changed now.

\section{I: Mhmmm, why?}

S: Er (- -) for the reason that (-) it is actually quite easy to use, which I did not expect, and that you (-) actually can have a lot of fun with it. (Interview 10D, position 10-12) 
For eleven students, working with HoloLens had a positive effect on their subjectspecific interest. In particular, the possibility to study the molecules in 3D and from different perspectives stimulated their interest. One student explains it as follows:

S: Mhm, my motivation (-) yes, because it suddenly seems more real. Before, or when you have to identify molecules on a piece of paper, it is a bit, uh, I do not know, a bit boring. But when you see it in front of you, and you can change the layers, then my imagination increases, and with the imagination also the interest increases. (Interview 08C, position 40)

For seven of the eighteen students, working with HoloLens had no influence on their interest in the subject content.

3.2.3. Research Question 2: To What Extent Is the Learning Process Supported by Working with HoloLens from the Learners' Point of View?

We were very interested to learn to what extent the students had experienced HoloLens as a support for the individual learning process. Almost all students (15 out of 18) told us that they believe working with HoloLens had a positive effect on their learning. The possibility to observe and explore an object in 3D is considered particularly valuable for the learning process:

S: I think, because (-) if you only have the $2 D$ image, (-) then you have somewhat of a picture, but you cannot quite imagine it (-) in three dimensions. And when you really see it in front of you and you can experiment with it yourself, (-) then you learn (-) learn it (-) in yet another way. Or (-) experience it in a different way. (Interview 10C, position 57-61)

$S: \ldots$ and you can refer to $3 D$ models and if you can do that, it is very supportive also for the (-) logic and for the whole comprehension. (Interview 10B, position 33)

Specific functions of the application were also positively highlighted, such as the possibility to zoom into the object, to enlarge certain aspects, or to have additional information displayed. In this way, the students could work individually according to their interests or adaptively according to their previous knowledge, which in their view supported the learning process:

S: Yes. (- -) Yes, that when I was interested in something, I could (-) just do something. So that I could zoom in or click on it and get information, like now (- -) um (-) yes, I could, discover (-) inquire and explore (laugh) whatever interested me. (Interview 08B, position 101-103)

S: I found the (-) the view with the, um (-) alpha-helix and the beta-sheet, I found that really helpful, that we can see it like this (-) that you can superimpose it and see it like this again ... I found that really helpful. (Interview 08D, position 52-54)

S: Well, the learning app has really given many (-) tools, (-) what you can do. I mean this possibility to examine it in $3 D$ in general, to enlarge it, to resize it, different ways of displaying it. Uh, it simply gives you additional possibilities and tools, I would say. So, it reinforces it [the learning process]. (Interview 12A, position 41)

Finally, the non-ordinary experience was also considered to be valuable. The fact that working with HoloLens was something completely new and unique for the students suggests that what they learnt will, perhaps, be remembered for longer:

S: Because it is something special. Mhhh, uh, I still remember it weeks later, right. (Interview 03B, position 113)

However, we assume that this effect would probably fade with regular use of HoloLens. 
3.2.4. Research Question 3: What Should Be Considered When Working with HoloLens in Terms of the Didactic Setting?

The students were explicitly asked about different aspects regarding the didactic setting. Compared with working without HoloLens, the students see both advantages (15 out of 18 ) and disadvantages (16 out of 18 ).

Although this is not directly related to the didactic setting, several students critically remark that the cost of the equipment is very high. Especially when working with a whole class, the acquisition costs are significant. In addition, the students believe that the technical skills of teachers may be a problem. In the work phase, which they experienced themselves, they noticed that technical problems can occur with HoloLens. Such problems need to be solved by the teacher and require certain technical competences, as stated by this student:

S: Um (-) another disadvantage is that you somehow have to have a technophile (- -) expert, maybe not quite, but just someone who can install the whole thing somehow and synchronize it and is available if something does not work. (Interview 10A, position 130)

Another disadvantage is seen in the fact that the experience is volatile and there is no writing process during learning with HoloLens. Since written materials are considered important for learning (both texts to learn from and self-written content that was learnt), HoloLens cannot replace traditional teaching:

S: Personally, I am a person who learns a lot when I have to write something down. But I also grew up writing everything by hand. And if I have to write it down, like for myself, a formula, $\mathrm{COOH}$ or something, I then can (-) like (-) remember better and I do not know how you could incorporate that with HoloLens. In the end, you still have to learn which molecule is structured in what way, for example. And that could be lost a little bit, I think. (Interview 08C, position 82)

S: Um (- -) yes, you can (-) you have seen the (-) but I do not have it like somehow (-) in contrast to a paper form, I have the molecules underlined afterwards and I can look at it again later and I know what I did there, and, and (-) here it is really just memory and what I have actually done now. It supports, but you do not have anything fixed afterwards... so it is in your hands again if you want to look at it again or something. So, if you only work with this, you still have to find some way to store it or something. (Interview 08D, position 74-76)

It is noted that the device cannot be used for all subject matter or topics, as there may be no corresponding application available. Therefore, the technology can only be used in a limited way. Explicitly, a student stated that HoloLens supports a specific type of learning, which may not be suitable for all learners:

S: I think it is simply limited in (-) the (-) choice of topics, so how (-) the possibilities, what is there. There are (-) there (-) and it will probably also (-) be presented in the form in which the program is designed (-) and maybe that corresponds to you as a teacher or maybe to you as a student (-) or that does not quite correspond (-) the way you can learn it, but also (-) with today's teaching materials (-) some learn better that way, others that way (-) from that point of view (-) yes. (Interview 09C, position 67)

After all that has been said so far, it is clear that for the students, HoloLens cannot replace traditional methods of teaching and current learning materials, but it can be a valuable supplement:

S: Hm. Yes, as a complementary tool I think it is certainly really great. You cannot work with the HoloLens only. You almost cannot (-). But it, uh, supports the traditional ways of how you learn. For sure. (-) Who knows, maybe, uh, the HoloLens will become a traditional, traditional (-) uh learning opportunity. So, I do not know. Exciting. (-) It is exciting! (Interview 09B, position 46)

The students are convinced that HoloLens offers the possibility to design lessons differently and thus to promote the motivation of learners as well as to support learning 
processes. HoloLens' ability to allow all learners to see the same content, to work collaboratively on a task with the support of HoloLens, and for the teacher to be able to see into the learners' learning are considered partic-ularly valuable:

S: Well, I think with regard to the subject content, what we have already said with the (-) $3 D$ and just that you can illustrate something. Regarding the method, it is simply a ... a way of creating something new in class, it gets away from endless sheets of paper and books (-), it can also be a very big (-) source of motivation for the students, maybe also to get them excited about technology, which, after all, is not the stupidest idea in the subject of science and technology. And um (-) yes, I think it is simply (-) a, a method of working (-) together on something that you have never done before, which is then also (-) another (-) there, it also needs a lot of cooperation and (-) that is never wrong. (Interview 10B, position 82)

S: But also in the fact that you (-), that you can interact with each other, so you can stand around the molecule in twos, threes, you can discuss with each other, you can um (-) I can ... for example, rotate the protein while my partner could also see it the same way. But at the same time, he saw it from a different perspective, so you can also come to an added value with (-) so (--) on the social level. (Interview 10A, position 97)

S: You can actually give open assignments, but if I have understood correctly, Mr. Beck [the lecturer] was always able to look into our work. You do have this control by being able to get involved. (Interview 08A, position 41)

From the students' point of view, the technology definitely bears the danger of distracting from the actual task. However, they also see this danger with all other technologies, as this student reasonably explains:

S: That (-) depends on how concentrated you work. I think there are both, if you are really interested in the subject content and want to study and learn, it can be extremely supportive, when you just want to (-) try it out, yes, then (-) it is like a laptop or a mobile phone or something, I mean, I can do both on the laptop. Either I am really concentrated and I am writing my texts and I am studying or whatever, or I am watching Netflix (laughing). And I think it is similar here, so you have a lot of possibilities to just turn and zoom the molecule, so (-) if you do not want to learn, then (-) it does not necessarily support you. (Interview 08D, position 64-68)

The interviewed students will later work as teachers at the lower secondary school level. We therefore wanted to learn from them about their opinion of the use of HoloLens at this school level. All the students interviewed could imagine that HoloLens could be used in teaching at the lower secondary level. The students think that it would certainly be very motivating for the pupils and that there are different opportunities to use HoloLens. Nevertheless, the students suspect that it would probably take a rather long time to introduce the pupils to the technology:

S: If you want to take the effort and introduce them to it (-), which is something I can very well imagine, perhaps once in a school project week, when you have more time to do this, you can use it in many projects, and I think the pupils also like that very much. (Interview 10B, position 96)

However, 6 out of 18 students see problematic issues, including the high costs for the initial purchase and the possible wear and tear of the devices due to the pupils not handling them carefully. Regarding the didactic setting, the students see the danger that the pupils might be rather distracted by the technology:

S: Um, actually yes, but um, it is perhaps a bit (-) more difficult. That, on the one hand, that it is handled carefully (-) ahm (-), that it does not just create a huge chaos. (laughter) (-) Because (-) um, because then the HoloLens really, um, because the focus is then simply on the device and not on the things that you actually want to look at. (Interview 11B, position 69) 
Furthermore, 16 out of 18 students would be comfortable working with HoloLens themselves as a teacher with pupils at the lower secondary level. Two students were rather skeptical, especially due to their attitude towards technology, as this student explains:

S: Possibly. Carefully, yes, ahm. As I said, I am not a big fan of technology. I do not think you have to bring electronics into everything. Because they already have a lot of it in their leisure time or because it is already a huge topic anyway. I would rather give a balance to it. Somehow show that it can also be interesting without it. And there are so many possibilities, I think. And from that point of view, I would never rule it out, I think, but yes, I am perhaps more the traditional type. (Interview 08A, position 59)

\section{Discussion}

In this exploratory study, Microsoft HoloLens was used in the context of teacher education. HoloLens is a rather new technical device that first became available at the end of March 2016. HoloLens is a head-mounted display that facilitates teaching and learning with Augmented Reality. Our study therefore focused on two aspects that have hardly been addressed in previous studies. On the one hand, only a few studies to date have dealt with wearable technologies, such as gloves, bracelets, or head-mounted displays, in the education sector [4,19]; on the other hand, studies at the tertiary education level, especially with prospective teachers, are significantly under-represented [9].

The students participating in the study were very motivated to take part and to work with the new technology. However, according to their responses, they had hardly any theoretical or practical experience with AR applications. Apparently, such technologies are barely used in teacher education and prospective teachers have little opportunity to gain first-hand experience and thereby develop abilities, a finding that was also made in a recently published international study [30]. In teacher education in particular, this causes long-term effects. If prospective teachers are not socialized with digital media during their education and can engage with the advantages and challenges during that time, they will presumably also use digital media less in their own teaching activities later on. Although the use of digital media in the classroom can of course be limited by equipment-based issues, such as limited access, studies show that the most relevant factor is the teacher. If the teacher is not experienced and comfortable using technology, he or she is unlikely to use it in the classroom. Evidence so far suggests that this is one of the most critical features of technology integration [10].

\subsection{Impact on Learning with the Use of HoloLens}

Regarding Research Questions 1 and 2, the results of our study show that the students appreciated working with AR. The students were enthusiastic about the technology and would appreciate the use of HoloLens devices in teacher education. They stated that their motivation and interest were increased and that learning processes can be supported in various ways. These results go along with the findings already made in other studies (e.g., $[4,6,8,9,14])$.

The usability was rated positively by the students. After a short introduction, the students felt comfortable operating and working with HoloLens. However, most of the students experienced minor difficulties, with five students experiencing major problems. The students realized that technical skills and know-how must be acquired in order to work with the devices. This can be confirmed by the project team. Much effort was required from the members of the project team in order to familiarize themselves with the devices and the application, to set them up, and to prepare the corresponding teaching unit. Nevertheless, the participants' reactions suggest it is very valuable and reasonable to work with such technologies in the context of teacher education. Even if students do not have the opportunity to work with this technology in their own classrooms later on, they can be sensitized to digital media and gain experience that will motivate them to use new technologies in the classroom themselves. According to recent studies, motivation is 
considered a crucial condition for technology integration [11]. In this respect, it would be very desirable if digital media were increasingly used in teacher education.

\subsection{Considerations on the Didactic Setting When Working with HoloLens}

Previous studies have shown that using technologies to support teaching and learning processes does not have a positive effect in general. Rather, it is how they are used during teaching that is important [11]. This aspect, of course, also applies to the work with HoloLens and was explicitly addressed in the context of the study in Research Question 3 (What should be considered when working with HoloLens in terms of the didactic setting?).

For the conception of the teaching unit, it was considered which content AR could be expected to add significant value to, enabling the exploration of previously not adequately accessible content. As the students noticed, not for every desired subject or topic is an application available for the HoloLens operating system. The problem of it not being possible to produce materials oneself, to adapt them, or to buy them will probably persist for some time to come, limiting the use of this technology. In addition, the costs for the devices are very high. However, with a one-time purchase, the devices can then be used over a long period of time and the acquisition costs will probably decrease over the next few years. However, details on the wear and tear of the devices (e.g., whether the devices can withstand frequent use in educational settings) are unknown. In this respect, it is important to check whether the devices and their features are suitable for the intended purpose and whether it is reasonable to acquire them.

As Augmented Reality is a new technology, it will initially require more effort from teachers to prepare a learning unit. In addition, more technical skills are needed with this technology than with other technologies that are already in use. To ensure that learners do not get lost in the technology, a specific assignment is essential.

A HoloLens device weighs slightly more than $500 \mathrm{~g}$ and is worn as a HMD. Although $500 \mathrm{~g}$ is not much in principle, it is clearly noticeable after some time. Therefore, with the current specifications the working phase should be limited in time and should not last longer than approximately $15 \mathrm{~min}$.

HoloLens provides an environment where learners can discover and explore learning content individually or collaboratively. As the students themselves noticed, the learning experience is volatile. HoloLens generally allows objects in the environment to be perceived and used while wearing the device. In principle, learners can therefore use paper documents as well while working with HoloLens. However, since wearing the devices is rather uncomfortable after a while, the paperwork should be outsourced. The work phase with HoloLens should therefore be embedded in a teaching unit in which the learning content explored with HoloLens is introduced and further elaborated upon.

The findings from our study indicate that different aspects must be considered in relation to the didactic setting. Firstly, traditional didactic principles of learning have to be followed. These should be complemented by specific principles inherent in digital technologies. Secondly, the ergonomics of the device also need to be taken into account. This means that the teaching unit should not last too long, as the head-mounted display tends to become uncomfortable, which in itself causes a learning distraction. Furthermore, the didactic setting should be developed considering the possibilities of increased interaction in order to avoid AR elements being used only as illustrative material, such as a picture or a non-interactive video.

\subsection{Reflections on the Possibilities and Pedagogical Approaches Offered When Working with HoloLens}

So far, Research Questions 1, 2, and 3 have been addressed. In this section, we conclude with our reflections on Research Question 4 (What are the possibilities and pedagogical approaches offered by working with HoloLens?).

"Augmented reality technologies allow learners the freedom to actively experience digital content and integrate new information into their existing knowledge base on an individualized path of discovery" [1] (p. 1393). With HoloLens using the MoleGram 
Scientist application, there is the possibility to zoom in, rotate and flip content, and show different representations of objects otherwise not accessible. From the interviews with the students, it is evident that this kind of learning, involving exploration, individual discovery, and engaging with the content according to one's own prior knowledge and interests, was very much appreciated. From their point of view, this also supported the learning process. This way of learning can be assigned to constructivism, which is, according to Garzòn and colleagues [18] (p. 3), "the most popular learning theory in educational technology".

Social constructivism [31] is based on the assumption that social interaction is of high significance in the development of cognition, and digital technologies can support cooperative learning in many ways. HoloLens supports collaborative ways of working too, as the glasses can be synchronized. This allows for several people to see the same content and to work together on the same content. As other studies have shown that the greatest impact was achieved when interventions followed the collaborative pedagogical approach [18], our teaching unit was designed as a collaborative task too, and the students very much appreciated the possibility of collaborative working. With this option, the teacher can also participate in the learning activity, show the learners how to do something, collaborate, or provide coaching.

Another attractive feature of HoloLens is the possibility to record all the activities on video. This enables teachers or learners to analyze the learning process afterwards. On the one hand, this can be helpful for the learners, as they can watch the work phase again later or evaluate their own learning. On the other hand, the teacher can use the videos to assess the work phase. It also opens new possibilities for research on teaching and learning. The topic of videography in teacher education has been studied intensively in recent years (e.g., [32-35]), but it seems that no work has yet been done on this topic that deals with videos of this kind. It would be particularly interesting to be able to continue working with HoloLens in this context.

\subsection{Considerations for Future Research}

This study is an exploratory study with only a limited number of participants. Moreover, the students who participated in the study volunteered to do so. In this respect, the study has various limitations. For future research projects, it would therefore be very desirable to include a larger group of students in the study. It would also be very interesting if, for example, all learners of a particular course could be involved, so that not only students with a specific interest in the project volunteer and take part in the study. This would make it possible to gain deeper insight into the experiences of teachers and learners.

Most interventions with AR in education are relatively short. In the meta-analysis of Garzón, Kinshuk, Baldiris, Gutiérrez, and Pavón [18], 93\% of the interventions lasted less than one month. The positive impact of AR on learning could thus be attributed to a novelty effect. In our study too, only one single work phase with HoloLens was conceptualized and realized. It would therefore be most desirable to conduct long-term studies in the future to investigate the long-term effects.

In the context of our study, it would be very interesting to examine whether HoloLens could be used with other content as well as with other subjects. Both the project team and the students believe that the devices could be used effectively in other areas. Moreover, it would also be very exciting to look more closely at the video recordings that can be made of the learners' learning activities with HoloLens. These video recordings could be used as an additional learning material, as well as an object of research and could be studied in more detail.

\section{Conclusions}

To date, hardly any studies have been conducted on the application of AR technologies in teacher education [36]. In this respect, the results of this paper provide new findings that may be relevant to the education sector in general and teacher education in particular. Our results show that the use of AR is very useful in teacher education and that prospective 
teachers are not averse to this technology's integration. In the context of teacher education, the use of such technologies can be beneficial in two ways. On the one hand, the teaching processes of students can be positively supported, as has already been shown in other studies. On the other hand, the prospective teachers can gain experience and deal with the advantages and challenges of such technologies. This enables them to examine and develop their attitude towards the use of digital media in the classroom. For the integration of technology in the classroom, such experiences and the individual teacher's comfort with the technology are crucial. As the results of international studies show, teachers have rarely used technology in the classroom to date [11]. In order to change this situation, a shift in teacher education in this regard is imperative.

In this study, a new technology was used, which is rarely encountered in the field of education, especially in teacher education. This decision was made deliberately to investigate the extent to which such innovative concepts are accepted and can be implemented in teacher education. At present, the devices are too expensive for extensive use in the education sector and are not particularly suitable because of the limitations already mentioned; however, through the improvement and further development of such devices, their comprehensive use in the educational setting will become more likely. However, the results clearly show how important and beneficial it is to use AR in teacher education. In addition, for this purpose, other technologies can, of course, equally be employed.

Supplementary Materials: The following are available online at https:/ / www.mdpi.com/article/10 $.3390 / \mathrm{mti5080045/s1,} \mathrm{Video} \mathrm{S1:} \mathrm{Example} \mathrm{section} \mathrm{of} \mathrm{the} \mathrm{collaborative} \mathrm{work} \mathrm{task} \mathrm{with} \mathrm{HoloLens.}$

Author Contributions: Conceptualization, C.W. and W.B.; methodology, C.W. and W.B.; software, MoleGram Scientist software development, J.A.H.; formal analysis, W.B., F.F., C.W. and A.D.; investigation, W.B., F.F., A.D. and C.W.; data curation, F.F., A.D., W.B. and C.W.; writing-original draft preparation, C.W.; writing-review and editing, F.F., W.B. and A.D.; visualization, F.F., W.B. and C.W.; project administration, C.W.; funding acquisition, C.W. and W.B. All authors have read and agreed to the published version of the manuscript.

Funding: This research was funded by the Swiss National Science Foundation (SNSF), Digital Lives 2018, grant number: 10DL19_183135.

Data Availability Statement: The data from the semi-structured interviews presented in this study are openly available in FORSBASE at DOI Nr: 10.23662/FORS-DS-1282-1. The paper-based survey and the video recordings of the lesson are available on request from the corresponding author. The data are not publicly available due to the limited number of cases for the questionnaire data and issues of data protection for the videos.

Acknowledgments: The authors would like to thank the staff and students at the University of Teacher Education for their participation and generous support. Usage of the MOE program environment within MoleGram Scientist by kind permission of The Chemical Computing Group Inc. (Montreal, Canada).

Conflicts of Interest: The authors declare no conflict of interest. The funders as well as the company Microsoft have no role in the design of the study; in the collection, analyses, or interpretation of data; in the writing of the manuscript; or in the decision to publish the results.

\section{References}

1. Wang, M.; Callaghan, V.; Bernhardt, J.; White, K.; Peña-Rios, A. Augmented reality in education and training: Pedagogical approaches and illustrative case studies. J. Ambient. Intell. Humaniz. Comput. 2018, 9, 1391-1402. [CrossRef]

2. Anshari, M.; Almunawar, M.N.; Shahrill, M.; Wicaksono, D.K.; Huda, M. Smartphones usage in the classrooms: Learning aid or interference? Educ. Inf. Technol. 2017, 22, 3063-3079. [CrossRef]

3. Martín-Gutiérrez, J.; Fabiani, P.; Benesova, W.; Meneses, M.D.; Mora, C.E. Augmented reality to promote collaborative and autonomous learning in higher education. Comput. Hum. Behav. 2015, 51, 752-761. [CrossRef]

4. Akçayır, M.; Akçayır, G. Advantages and challenges associated with augmented reality for education: A systematic review of the literature. Educ. Res. Rev. 2017, 20,1-11. [CrossRef]

5. Carmigniani, J.; Furht, B. Augmented Reality: An Overview. In Handbook of Augmented Reality; Springer: New York, NY, USA, 2011; pp. 3-46, ISBN 978-1-4614-0063-9. 
6. Nincarean, D.; Alia, M.B.; Halim, N.D.A.; Rahman, M.H.A. Mobile augmented reality: The potential for education. Proced. Soc. Behav. Sci. 2013, 103, 657-664. [CrossRef]

7. Milgram, P.; Takemura, H.; Utsumi, A.; Kishino, F. Augmented Reality: A Class of Displays on the Reality-Virtuality Continuum. In Telemanipulator and Telepresence Technologies; SPIE-The International Society for Optical Engineering: Washington, DC, USA, 1994; Volume 2351, pp. 282-292. [CrossRef]

8. Yuen, S.C.-Y.; Yaoyuneyong, G.; Johnson, E. Augmented reality: An overview and five directions for AR in education. J. Educ. Technol. Dev. Exch. 2011, 4, 119-140. [CrossRef]

9. Garzón, J.; Pavón, J.; Baldiris, S. Systematic review and meta-analysis of augmented reality in educational settings. Virtual Real. 2019, 23, 447-459. [CrossRef]

10. Wood, E.; Mueller, J.; Willoughby, T.; Specht, J.; Deyoung, T. Teachers' Perceptions: Barriers and Supports to Using Technology in the Classroom. Educ. Commun. Inf. 2005, 5, 183-206. [CrossRef]

11. Backfisch, I.; Lachner, A.; Stürmer, K.; Scheiter, K. Variability of Teachers' Technology Integration in the Classroom: A Matter of Utility! Comput. Educ. 2021, 166, 104159. [CrossRef]

12. Dunleavy, M. Design Principles for Augmented Reality Learning. Tech. Trends 2014, 58, 28-34. [CrossRef]

13. Peterson, C.N.; Tavana, S.Z.; Akinleye, O.P.; Johnson, W.H.; Berkmen, M.B. An Idea to Explore: Use of Augmented Reality for Teaching Three-dimensional Biomolecular Structures. Biochem. Mol. Biol. Educ. 2020, 48, 276-282. [CrossRef]

14. Dunleavy, M.; Dede, C.; Mitchell, R. Affordances and Limitations of Immersive Participatory Augmented Reality Simulations for Teaching and Learning. J. Sci. Educ. Technol. 2009, 18, 7-22. [CrossRef]

15. Safadel, P.; White, D. Facilitating Molecular Biology Teaching by Using Augmented Reality (AR) and Protein Data Bank (PDB). Tech. Trends 2019, 63, 188-193. [CrossRef]

16. Garcia-Bonete, M.-J.; Jensen, M.; Katona, G. A Practical Guide to Developing Virtual and Augmented Reality Exercises for Teaching Structural Biology: VR and AR for Teaching Structural Biology. Biochem. Mol. Biol. Educ. 2019, 47, 16-24. [CrossRef] [PubMed]

17. Wu, H.-K.; Lee, S.W.-Y.; Chang, H.-Y.; Liang, J.-C. Current Status, Opportunities and Challenges of Augmented Reality in Education. Comput. Educ. 2013, 62, 41-49. [CrossRef]

18. Garzón, J.; Kinshuk; Baldiris, S.; Gutiérrez, J.; Pavón, J. How Do Pedagogical Approaches Affect the Impact of Augmented Reality on Education? A Meta-Analysis and Research Synthesis. Educ. Res. Rev. 2020, 31, 100334. [CrossRef]

19. Altinpulluk, H. Determining the Trends of Using Augmented Reality in Education between 2006-2016. Educ. Inf. Technol. 2019, 24, 1089-1114. [CrossRef]

20. Berman, H.; Henrick, K.; Nakamura, H. Announcing the Worldwide Protein Data Bank. Nat. Struct. Mol. Biol. 2003, 10, 980. [CrossRef]

21. Molecular Operating Environment (MOE); Chemical Computing Group ULC: Montreal, QC, Canada, 2017. Available online: https:/ / www.chemcomp.com/Products.htm (accessed on 7 August 2021).

22. Kesim, M.; Ozarslan, Y. Augmented Reality in Education: Current Technologies and the Potential for Education. Procedia-Soc. Behav. Sci. 2012, 47, 297-302. [CrossRef]

23. Rutenber, E.E.; McPhee, F.; Kaplan, A.P.; Gallion, S.L.; Hogan, J.C.; Craik, C.S.; Stroud, R.M. A New Class of HIV-1 Protease Inhibitor: The Crystallographic Structure, Inhibition and Chemical Synthesis of an Aminimide Peptide Isostere. Bioorg. Med. Chem. 1996, 4, 1545-1558. [CrossRef]

24. Rheinberg, F.; Vollmeyer, R.; Burns, B.D. FAM: Ein Fragebogen Zur Erfassung Aktueller Motivation in Lern- Und Leistungssituationen. Diagnostica 2001, 47, 57-66. [CrossRef]

25. Neyer, F.J.; Felber, J.; Gebhardt, C. Entwicklung Und Validierung Einer Kurzskala Zur Erfassung von Technikbereitschaft. Diagnostica 2012, 58, 87-99. [CrossRef]

26. Beierlein, C.; Kovaleva, A.; Kemper, C.J.; Rammstedt, B. Ein Messinstrument Zur Erfassung Subjektiver Kompetenzerwartungen: Allgemeine Selbstwirksamkeit Kurzskala (ASKU); GESIS-Leibniz-Institut für Sozialwissenschaften: Mannheim, Germany, 2012; pp. 1-24.

27. Mayring, P. Qualitative Inhaltsanalyse: Grundlagen und Techniken; Beltz Verlag: Weinheim, Germany, 2015; ISBN 978-3-407-25730-7.

28. Mayring, P. Qualitative Content Analysis: Demarcation, Varieties, Developments. Qual. Soc. Res. 2019, 20. [CrossRef]

29. Zhang, Y.; Wildemuth, B.M. Qualitative Analysis of Content. In Applications of Social Research Methods to Questions in Information and Library Science; Wildemuth, B.M., Ed.; Libraries Unlimited: Santa Barbara, CA, USA, 2017; pp. 318-329, ISBN 978-1-4408-3904-7.

30. Eickelmann, B.; Bos, W.; Gerick, J.; Goldhammer, F.; Schaumburg, H.; Schwippert, K.; Senkbeil, M.; Vahrenhold, J. ICILS 2018 \#Deutschland Computer- Und Informationsbezogene Kompetenzen von Schülerinnen Und Schülern im Zweiten Internationalen Vergleich Und Kompetenzen im Bereich Computational Thinking; Waxmann Verlag: Münster, Germany, 2019; ISBN 978-3-8309-4000-5.

31. Vygotsky, L.S. Mind in Society: Development of Higher Psychological Processes; Harvard University Press: Cambridge, MA, USA, 1978; ISBN 978-0-674-57628-5.

32. Tripp, T.; Rich, P. Using Video to Analyze One's Own Teaching: Video Self-Analysis. Br. J. Educ. Technol. 2012, 43, 678-704. [CrossRef]

33. Marsh, B.; Mitchell, N. The Role of Video in Teacher Professional Development. Teach. Dev. 2014, 18, 403-417. [CrossRef]

34. Hamel, C.; Viau-Guay, A.; Nkuyubwatsi, B. Using Video to Support Teachers' Reflective Practice: A Literature Review. Cogent Educ. 2019, 6, 1-14. [CrossRef] 
35. Gaudin, C.; Chaliès, S. Video Viewing in Teacher Education and Professional Development: A Literature Review. Educ. Res. Rev. 2015, 16, 41-67. [CrossRef]

36. Buchner, J.; Zumbach, J. Augmented Reality in Teacher Education. A Framework to Support Teachers' Technological Pedagogical Content Knowledge. Ital. J. Educ. Technol. 2020, 28, 106-120. [CrossRef] 